\title{
In vitro activity of Piper sarmentosum ethanol leaf extract against Toxoplasma gondii tachyzoites
}

\author{
Kumareswaran Devanthran ${ }^{1}$, Zasmy Unyah ${ }^{1}$, Roslaini Abdul Majid ${ }^{1}$ and Wan \\ Omar Abdullah ${ }^{2 *}$ \\ ${ }^{1}$ Medical Parasitology and Entomology Unit, Department of Medical Microbiology and Parasitology, Faculty of Medicine and \\ Health Sciences, Universiti Putra Malaysia, 43300 Serdang, Selangor Darul Ehsan, ${ }^{2}$ Department of Medical Sciences, Faculty \\ of Medicine and Health Sciences, Islamic Science University of Malaysia, 55100 Kuala Lumpur, Malaysia
}

*For correspondence: Email: wanomar@usim.edu.my; Tel: +60 12-2293294

Sent for review: 11 July 2015

Revised accepted: 19 October 2017

\begin{abstract}
Purpose: To evaluate the activity of the ethanol leaf extract of Piper sarmentosum against toxoplasmosis.

Methods: An in vitro anti-Toxoplasma study was conducted using Vero cells as a host for T. gondii. Clindamycin used as the reference drug. Light microscopy technique was used to study the in situ antiparasitic activity of T. gondii. Non-toxic concentrations of the ethanol extract for Vero cells were determined by methyl thiazolyl tetrazolium (MTT) cell proliferation. The presence of Toxoplasma gondii was observed by Giemsa staining.

Results: The results showed that significant $(p<0.05)$ anti-toxoplasma activity of the ethanol extract, though lower than that of clindamycin (control drug), was achieved, with half-maximal inhibitory concentration $\left(I C_{50}\right)$ of 12.4 and $7.2 \mu \mathrm{g} / \mathrm{mL}$ for the extract and reference drug, respectively. After 24 hours of exposure to the extract, the inoculated Vero cells showed lower parasitemia and no remarkable morphological changes.

Conclusion: The findings demonstrate that the ethanol extract of $P$. sarmentosum leaves are active against toxoplasmosis in vitro. However, further studies are required to determine the therapeutic significance of these findings in vivo.
\end{abstract}

Keywords: Toxoplasma gondii, Piper sarmentosum, Vero cell, Toxoplasmosis, Antiparasitic

\begin{abstract}
Tropical Journal of Pharmaceutical Research is indexed by Science Citation Index (SciSearch), Scopus, International Pharmaceutical Abstract, Chemical Abstracts, Embase, Index Copernicus, EBSCO, African Index Medicus, JournalSeek, Journal Citation Reports/Science Edition, Directory of Open Access Journals (DOAJ), African Journal Online, Bioline International, Open-J-Gate and Pharmacy Abstracts
\end{abstract}

\section{INTRODUCTION}

The sporozoan parasite, Toxoplasma gondii, is an intracellular coccidian tissue protozoa which is a common cause of toxoplasmosis in humans and animals, particularly immunocompromised hosts [1]. It is reported that approximately one third of the world's current population has been infected with this parasite [2]. The World Health Organization considers toxoplasmosis one of the major parasitic diseases infecting humans in the developing countries [3]. This status is reflected by the parasite's worldwide distribution and broad range of intermediate hosts [4] that have resulted in the infection of up to 1 billion people [5]. Most toxoplasmosis cases are reported in South America, Middle East and other lowincome countries with high seropositivity against $T$. gondii infection in either normal or immunecompromised hosts [6].

Toxoplasmosis is treated with a combination of sulfadiazine and pyrimethamine which are both key enzyme inhibitors in the biosynthesis of 
pyrimidines [6]. However, these drugs cause adverse reactions, including the suppression of bone marrow, teratogenic effects in the first trimester of pregnancy, and sulfadiazine hypersensitivity [7]. Other drugs such as clindamycin, atovaquone, daspone, trimethoprim, pentamidine, and azithromycin have also been used, but side-effects such as diarrhoea, nausea, abdominal pain, cholestatic hepatitis, hepatomegaly, and hepatitis have been reported [8]. Cultural knowledge pertaining to the application of medicinal plants in the treatment of parasitic infection represents a vital role in the discovery of safe and natural chemotherapeutic agents against toxoplasmosis [9].

Traditionally, the leaves of $P$. sarmentosum are used to treat malaria, coughs and colds, backache and joint pain, toothache, and worm infections [10]. Thus, the present study aims to investigate the anti-Toxoplasma activity of the ethanolic extract of $P$. sarmentosum leaves on $T$. gondii in the inoculated Vero cells.

\section{EXPERIMENTAL}

\section{Plant materials}

The leaves of Piper sarmentosum were collected from the vicinity of Universiti Putra Malaysia. Authentication of the species was based on published taxonomical nomenclatures [11]. The leaves of Piper sarmentosum were rinsed thoroughly with multiple changes of distilled water and oven-dried at $50{ }^{\circ} \mathrm{C}$ before being ground into powder. Extraction was carried out by macerating $100 \mathrm{~g}$ of powdered leaves with $500 \mathrm{~mL}$ of $95 \%$ ethanol at room temperature for $24 \mathrm{~h}$. The extract was then filtered through Whatman no. 1 filter paper. After filtration, the extract was evaporated under reduced pressure using rotary evaporation. The RPMI-1640 medium (Gibco BRL) was used as the solvent for the preparation of various dilutions of the ethanolic extract. Concentrated stock solution of each ethanolic extract was prepared by adding a known weight of each ethanolic extract to a known volume of RPMI-1640 medium, and then serially diluted (1:2) to obtain the working solutions at different final concentrations.

\section{Vero cell line}

Vero cells were maintained in a growth medium consisting of RPMI-1640 supplemented with 10 $\%$ FBS (Gibco BRL), (Gibco BRL), 100 units $/ \mathrm{mL}$ penicillin (Gibco BRL) and $100 \mu \mathrm{g} / \mathrm{mL}$ streptomycin (Gibco BRL). Clindamycin (SigmaAldrich Corp) was used as the reference control drug. The cells were cultured and maintained at $37^{\circ} \mathrm{C}$ in a humidified $5 \% \mathrm{CO}_{2}$ incubator.

\section{Toxoplasma gondii RH strain}

The tachyzoites from the virulent $\mathrm{RH}$ strain of $T$. gondii were harvested from the peritoneal fluid layer of infected Balb/c mice in phosphatebuffered saline (PBS), $\mathrm{pH}$ 7.2. The peritoneal fluid obtained was then centrifuged at $1500 \mathrm{rpm}$ for $10 \mathrm{~min}$ at room temperature to remove host cells and debris as mice host cells were found in the peritoneal fluid layer. The pellet was washed twice with RPMI-1640 supplemented with glutamine (2 raM), penicillin (100 units $/ \mathrm{mL}$ ), and streptomycin $(100 \mu \mathrm{g} / \mathrm{mL})$. The tachyzoites $T$. gondii were inoculated to the Vero cell and grown in a $25 \mathrm{~mL}$ tissue culture flask at $37^{\circ} \mathrm{C}$ in a humidified $5 \% \mathrm{CO}_{2}$ incubator.

\section{MTT assay}

Cytotoxicity of the ethanol extract of $P$. sarmentosum on Vero cells was determined using 3-(4, 5-dimethylthiazol-2-yl) -2,5diphenyltetrazolium bromide MTT assay which was published by Mosmann [12]; however, some modifications were made to this method. Vero cells were seeded at a density of $6 \times 10^{4}$ cells $/ \mathrm{mL}$ in each well of a 96 -well plate containing $100 \mu \mathrm{L}$ of the growth medium. The plate was incubated at $37 \stackrel{\circ}{\circ} \mathrm{C}$ in a humidified $5 \% \mathrm{CO}_{2}$ incubator for 24 hrs. The cells were treated with the ethanol extract of $P$. sarmentosum, which was serially diluted using the growth medium to obtain the various final concentrations of $200,100,50,25$, 12.5, 6.25 and $3.125 \mu \mathrm{g} / \mathrm{mL}$. $100 \mu \mathrm{L}$ of each concentration was added into each respective 96-well plate. In this study, clindamycin, a known drug for treating toxoplasmosis was used as the reference (positive) control drug, and RPMI was used as the control buffer. After $24 \mathrm{~h}$ of treatment, $200 \mu \mathrm{L}$ of the medium was aspirated out and $100 \mu \mathrm{L}$ of MTT - PBS (5 mg/mL) solution in RPMI medium in the ratio of $1: 9$ was added to each well. The plate was then covered with aluminium foil and incubated for $4 \mathrm{hrs}$ in a $37^{\circ} \mathrm{C}$ incubator. The medium was then discarded and $100 \mu \mathrm{L}$ of DMSO was added into each well to solubilise the dark-blue MTT formazan salt. The optical density was measured at $570 \mathrm{~nm}$ absorbance using a Dynex Microplate Reader; higher concentrations can cause toxicity in Vero cells. Growth inhibition (Gl) was calculated as in Eq 1.

GI $(\%)=\{(A t-A c) / A c\} 100$

where At and Ac are the absorbance of treated cells and control, respectively. 


\section{Determination of anti-Toxoplasma activity and cytotoxicity}

The inoculated Vero cells were harvested from the culture flask during the exponential growth of the cells at day 2 , post-inoculation, with the cell density of $6 \times 10^{4}$ cells $/ \mathrm{mL}$ cultured in 96-well plates. Following this, $3 \times 10^{5} \mathrm{~mL}$ of Toxoplasma gondii was added to each well with the parasite to cell ratio of $5: 1$ for Vero cell inoculation; this ratio was based on a previous study by Belloni [13]. Six hours after inoculation, the inoculated cells were washed twice with RPMI to remove any non-adherent parasites. After 18 hours of incubation, $200 \mu \mathrm{L}$ RPMI supplemented with $2 \%$ FBS was added to each well following the methods developed by Sheng [14]. After 24 hours of treatment, the anti- T. gondii activity and cytotoxicity of the ethanol extracts of $P$. sarmentosum were evaluated using the MTT method. The optical density reading on the microplate reader at $570 \mathrm{~nm}$ was represented by the mean of three independent experiments. The median inhibitory concentration $\left(\mathrm{IC}_{50}\right)$ value was calculated based on the concentration of ethanol extracts of $P$. sarmentosum and clindamycin that successfully inhibited $50 \%$ of $T$. gondii. AntiToxoplasma activity was expressed as selectivity index $(\mathrm{SI})$ based on the mean of the $\mathrm{IC}_{50}$ values for Vero cells, relative to the mean of the $I_{50}$ value of $T$. gondii as shown in in Eq 2 [15].

$\mathrm{SI}(\%)=\left(\mathrm{V}-\mathrm{IC} \mathrm{C}_{50} / \mathrm{T}-\mathrm{I} \mathrm{C}_{50}\right) 100$

where $\mathrm{V}-\mathrm{I} \mathrm{C}_{50}$ and $\mathrm{T}-\mathrm{IC}_{50}$ are the median inhibitory concentrations required to inhibit Vero cell and $T$. gondii, respectively.

\section{Microscopic examination of tachyzoites}

Vero cells were cultured on a glass cover slip inside a $35 \mathrm{~mm}$ petri dish until confluent, before being inoculated with $1 \times 10^{4}$ tachyzoites of $T$. gondii. After incubation for 4 hours, the monolayers formed on the glass cover slip were washed with a Hanks balanced salt solution (HBSS) (Gibco BRL). The ethanol extract of $P$. sarmentosum and clindamycin was then added to each glass cover slip and incubated for $24 \mathrm{~h}$ at $37^{\circ} \mathrm{C}$. After incubation, the glass cover slips were washed twice with HBSS and fixed with methanol prior to staining with Giemsa (SigmaAldrich Corp). All the prepared samples were observed using Nikon (model- Nikon Eclipse 50i) microscope and the images were captured using (NIS-Elements D, Japan). Qualitative analysis methods were used as an alternative to quantitative analysis.

\section{Statistical analysis}

The statistical analysis was performed using Student's t-test, and differences were considered significant at $p<0.05$. The results were analysed using the Statistical Package for Social Sciences (SPSS) version 22 for Windows and are presented as mean \pm standard deviation (SD).

\section{RESULTS}

\section{Anti-Toxoplasma activity}

The results of in vitro anti-Toxoplasma activity against the $T$. gondii $\mathrm{RH}$ strain and selectivity index are summarized in Table 1 and Figure 1. Anti-Toxoplasma activity was found in all the samples tested as well as high mortality. The highest anti-Toxoplasma activity was found in Clindamycin with $\mathrm{IC}_{50}=84.0 \pm 1.15 \mu \mathrm{g} / \mathrm{mL}$ and Selectivity index $=11.67$. Anti-Toxoplasma activity of the ethanol extracts of $P$. sarmentosum was comparable to clindamycin with $\mathrm{IC}_{50}=125.0$ $\pm 1.53 \mu \mathrm{g} / \mathrm{mL}$ and selectivity index $=10.08$.

\section{Morphology of anti-Toxoplasma in inoculated Vero cells}

Figures 2 and 3 illustrate the morphological effects of RPMI, clindamycin and $P$. sarmentosum extract on Vero cell and $T$. gondii inoculated Vero cells. After 24 hours, postinoculation, higher parasitemia were observed in the inoculated Vero cells (Figure 3). Tachyzoites of $T$. gondii could be observed inside the Vero cells; the tachyzoites were also adhered to the glass coverslip in the group treated with RPMI. However, when $50 \mu \mathrm{g} / \mathrm{mL}$ clindamycin and $P$. sarmentosum extract was added, the parasitemia drops and quantities of tachyzoites of $T$. gondii decreased sharply.

Table 1: Cytotoxicity, in vitro activity and selectivity index of ethanol extract of $P$. sarmentosum (with clindamycin as control) against $T$. gondii tachyzoites

\begin{tabular}{lccc}
\hline Tested material & $\begin{array}{c}\text { Cytotoxicity }\left(\mathbf{I C}_{\mathbf{5 0}},\right. \\
\boldsymbol{\mu g} / \mathbf{m L})\end{array}$ & $\begin{array}{c}\text { In vitro anti-Toxoplasma } \\
\text { assay }\left(\mathbf{I C} \mathbf{5 0}_{\mathbf{5 0}}, \boldsymbol{\mu g} / \mathbf{m L}\right)\end{array}$ & Selectivity index (SI) \\
\hline Clindamycin & $84 \pm 1.15$ & $7.2 \pm 1.53$ & 11.67 \\
$P$. sarmentosum & $125 \pm 1.53$ & $12.4 \pm 1.00$ & 10.08 \\
\hline
\end{tabular}




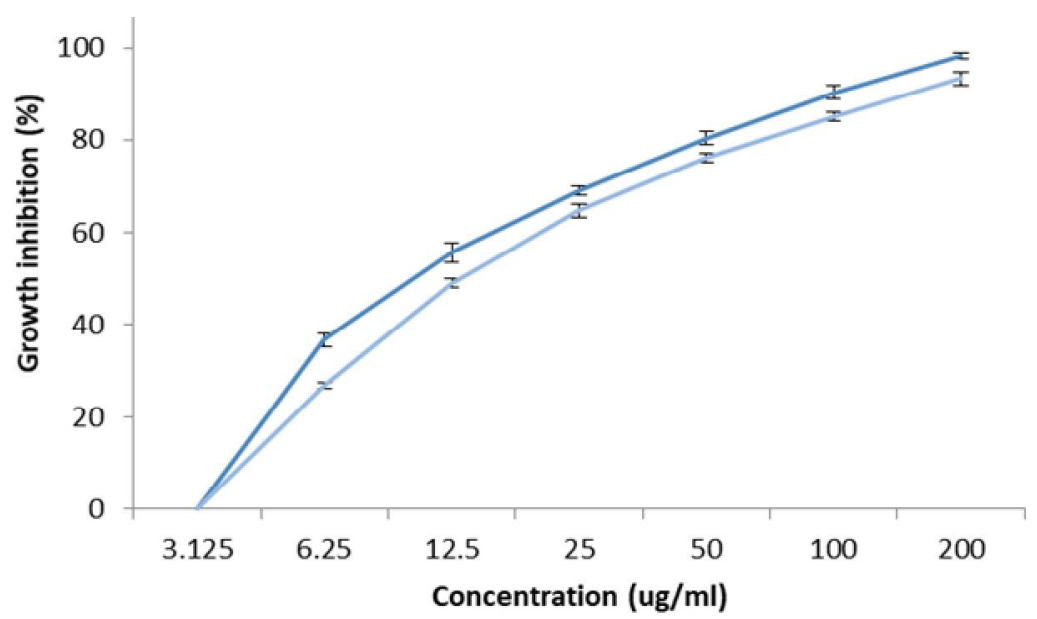

Figure 1: Anti-Toxoplasma activity of ethanol extracts of $P$. sarmentosum and clindamycin against $T$. gondii (---- Clindamycin, ------Piper)

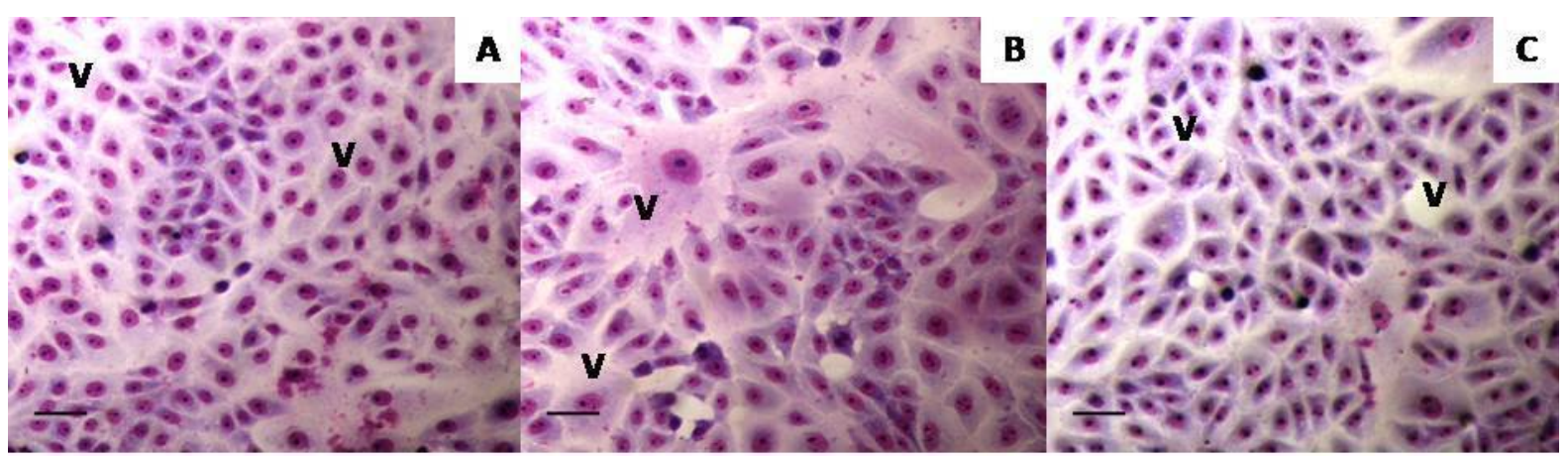

Figure 2: Morphology of Vero cells after cytotoxicity testing with A) Clindamycin, B) $P$. sarmentosum leaves and C) RPMI medium. After 24 hours of exposure to $50 \mu \mathrm{g} / \mathrm{mL}$ of $P$. sarmentosum leaves extract and clindamycin. Vero cells showed no remarkable morphological changes. Stained using Giemsa stain. (200 X magnification) Scale $20 \mu \mathrm{m}$

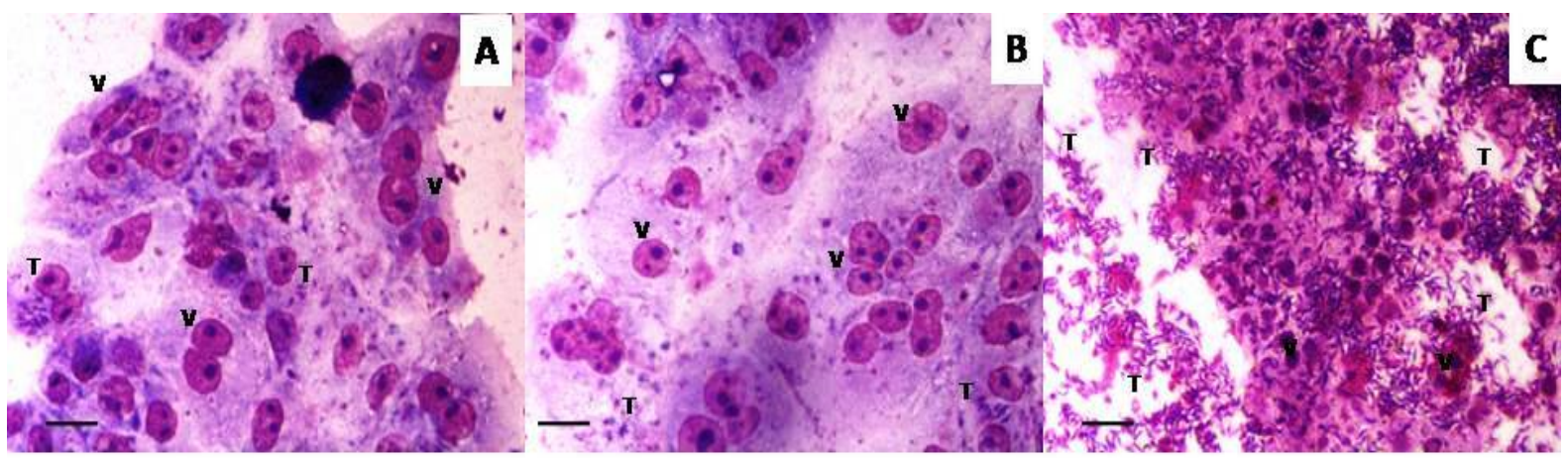

Figure 3: Morphology of Vero cells infected with $T$. gondii after adding a A) clindamycin, B) $P$. sarmentosum and C) RPMI medium. The tachyzoites of $T$. gondii $(\mathrm{T})$ can be seen inside the inoculated Vero cells (V), as well as adhered to the glass cover slip. After 24 hours, post-inoculation and exposure to the $50 \mu \mathrm{g} / \mathrm{mL}$ of $P$. sarmentosum extract and clindamycin, the inoculated Vero cells showed no remarkable morphological changes. Stained using Giemsa stain. A and B (400 X magnification), C (400 X magnification) Scale $10 \mu \mathrm{m}$

Following the first 24 hours, the tachyzoites of $T$. gondii were infrequently observed in the inoculated Vero cells. No counting was involved in this process, the method was exclusively based on observation. There was no significant change in morphology of Vero cells after exposure to $P$. sarmentosum extract (Figure 2 and Figure 3).

\section{DISCUSSION}

Parasitic diseases continue to have huge impact on human health, particularly in tropical regions [16]. New anti-parasitic drugs are urgently required in the treatment and control of parasitic infections such as toxoplasmosis [17]. The identification of an appropriate host to support 
the growth of the parasite presents a major challenge in anti-parasitic drug discovery. Scientific evidence documenting the antiparasitic properties of medicinal plant extract, derives mainly from in vitro studies. The main advantage of in vitro studies in this context is the ability to detect directly anti-parasitic activity of these extracts or compounds. It is necessary to ensure that the plant extracts are not toxic to the host and will not affect host performance [18]. Plant extracts can be involved in anti-parasitic activity assessment only if the parasitized host benefits from prolonged exposure to the extract. This net benefit can only be achieved if the antiparasitic properties of these extracts do not cause the adverse side effect on the host cell's morphology and performance [19].

Studies by Villena [20], demonstrated the efficacy of sulfadiazine and pyrimethamine combination in the treatment of toxoplasmosis. This combination leads to remarkable synergistic activity against the replicating form of $T$. gondii cysts in tissue through the sequential inhibition of parasite dihydropteroate synthase (DHPS) and dihydrofolate reductase (DHFR). These two major enzymes are responsible for the synthesis of the folate compounds that are essential for the survival and replication of parasites. However, several failures have been reported in the treatment of toxoplasmic encephalitis, chorioretinitis and congenital toxoplasmosis. These failures, relating to the host, may be due to several factors such as drug intolerance, malabsorption, poor compliance to the development of drug-resistant parasites, or lower levels of susceptibility to the parasite strain [20]. The ethanolic extract of $P$. sarmentosum was tested for potential cytotoxic activity in vitro against Vero cells. It was concluded that the extract was not toxic to Vero cells with $I_{50}$ values of more than $100 \mu \mathrm{g} / \mathrm{ml}$ (Figure 1).

It is imperative to first establish whether the plant extracts affect Vero cell performance using the cytotoxicity study. Following the findings (Table 1), the ethanol extracts of $P$. sarmentosum were further tested for antiToxoplasma and the potential (Figure 2). Anti-toxoplasma activity was found in the sample tested and high mortality of tachyzoites was observed. The extract also exhibited potential T. gondii inhibitory activity with the $I_{50}=12.4 \pm 2.08 \mu \mathrm{g} / \mathrm{mL}$ on the parasite growth (Figure 4). The results of the ethanol extracts of $P$. sarmentosum leaves were comparable to those of clindamycin $\left(\mathrm{IC}_{50}=7.2 \pm 1.52 \mu \mathrm{g} / \mathrm{mL}\right.$ ) (Figure 3 and Figure 4). A previous study by Saadatnia [21] concluded that the propagation of $T$. gondii parasites in Vero cells produced high yield and viability of tachyzoites, with minimal host cell contamination. Hence, Vero cells were used as the host cells for $T$. gondii in the present study to determine the anti-parasitic activity of the plant extracts.

Following the addition of plant extracts to monolayers of Vero cells, the cells remained metabolically active and viable after being infected with Toxoplasma gondii. This study confirmed that Toxoplasma gondii could invade Vero cells and proliferate quickly; it also demonstrated that plant extracts effectively inhibited the growth of Toxoplasma gondii, and were less toxic to Vero cells than clindamycin. This finding signifies that $P$. sarmentosum could potentially be an alternative to clindamycin for the treatment of toxoplasmosis; this warrants further study.

Normally the rapidly proliferating Toxoplasma gondii tachyzoites propagate by host cell lysis, regression, reattachment, and invasion of new host cells [22]. The significant changes observed in the morphology and confluence of Vero cells in an exclusively RPMI medium treated group (negative control) is likely due to the above fact. However, plant extract did not significantly affect the normal growth and morphology of the infected host cells, despite the potent anti $T$. gondii activities. The cells seemed to remain metabolically active and viable. In fact, cell proliferation and confluence was greater when compared to exposure to clindamycin. This observation verified that plant extracts had greater anti $T$. gondii activity and also had no selective toxicity against the infected host cells. Finally, this study confirms $P$. sarmentosum has potential as an alternative to clindamycin for the treatment of toxoplasmosis.

\section{CONCLUSION}

The ethanol leaf extract of $P$. sarmentosum shows potential anti-parasitic activity against $T$. gondii. Further study in the identification of the active compounds from this plant in Toxoplasma gondii infected animal models need to be carried out.

\section{DECLARATIONS}

\section{Acknowledgement}

This study was funded by Research University Grant Scheme, Universiti Putra Malaysia (nos. 04-02-12-1763RU, 04-02-12-1770RU). T. gondii was a gift from Department of Parasitology, Faculty of Medicine, Universiti Malaya. Vero cells 
were generously supplied by $\operatorname{Dr}$ Chee Hui Yee, Medical Microbiology Unit, Department of Medical Microbiology and Parasitology, Faculty of Medicine and Health Sciences, Universiti Putra Malaysia.

\section{Conflict of Interest}

No conflict of interest associated with this work.

\section{Contribution of Authors}

The authors declare that this work was done by the authors named in this article and all liabilities pertaining to claims relating to the content of this article will be borne by them.

\section{Open Access}

This is an Open Access article that uses a funding model which does not charge readers or their institutions for access and distributed under the terms of the Creative Commons Attribution License (http://creativecommons.org/licenses/by/ 4.0) and the Budapest Open Access Initiative (http://www.budapestopenaccessinitiative.org/rea d), which permit unrestricted use, distribution, and reproduction in any medium, provided the original work is properly credited.

\section{REFERENCES}

1. Osunkalu V, Akanmu S, Ofomah N, Onyiaorah I, Adediran A. Seroprevalence of Toxoplasma gondii IgG antibody in HIV-infected patients at the Lagos University Teaching Hospital. HIVIAIDS - Research and Palliative Care 2011; 3: 101-105

2. Hill DE, Chirukandoth S, Dubey JP. Biology and epidemiology of Toxoplasma gondii in man and animals. Anim. Health Res. Rev. 2005; 6: 41-61.

3. Kodym $P$, Malý $M$, Beran $O$, Jilich $D$, Rozsypal $H$, Machala L, Holub M. Incidence, immunological and clinical characteristics of reactivation of latent Toxoplasma gondii infection in HIV-infected patients. Epidemiol. Infect. 2014; 22: 1-8;

4. Jones JL, Parise ME, Fiore AE. Neglected parasitic infections in the United States: toxoplasmosis. Am J Trop Med Hyg 2014; 90: 794-799.

5. Tenter AM, Heckeroth AR, Weiss AR. Toxoplasma gondii: from animals to humans. Int. J. Parasitol. 2000:30; 1217-1258.

6. Kaye A. Toxoplasmosis: Diagnosis, treatment, and prevention in congenitally exposed infants. J. Pediatr. Health. Care. 2011; 25: 355-364.

7. Schmidt DR, Hogh B, Andersen O, Hansen ST, Dalhoff $K$, Petersen E. Treatment of infants with congenital toxoplasmosis: Tolerability plasma concentrations of sulfadiazine and pyrimethamine. Eur. J. Pediatr. 2006; 165: 19-25.

8. Georgiev VS. Management of toxoplasmosis. Drugs. 1994; $48: 179$

9. Zhai B, Clark J, Ling T, Connelly M, Medina-Bolivar F, Rivas F. Antimalarial Evaluation of the Chemical Constituents of Hairy Root Culture of Bixa. Orellana L. Molecules. 2014; 19: 756-766.

10. Lim C. Identification of alkaloids of pepper (Piper nigrum) and kadok (Piper sarmentosum) and the biotransformation of piperine using Aspergillus niger. (Master dissertation)pg 9

11. Wiart C. "Medicinal Plants of Asia and the Pacific," CRC Press, Boca Raton, 2006.

12. Mosmann T. Rapid colorimetric assay for cellular growth and survival: Application to proliferation and cytotoxicity assay. J Immunol Methods. 1983; 65: 55-63.

13. Belloni A, Villena I, Gomez JE, Pelloux H, Bonhomme A, Guenounou $M$, Pinon JM, Aubert $D$. Regulation of tumour necrosis factor alpha and its specific receptors during Toxoplasma gondii infection in human monocytic cells. Parasitol Res. 2003; 89: 207-13.

14. Sheng-Xia C, Liang W, Xu-Gan J, Yao-Yu F, Jian-Ping C. Anti-Toxoplasma gondii activity of GAS in vitro. $J$ Ethnopharmacol. 2008; 118:503-507.

15. Park H, Kim MS, Jeon BH, Kim TK, Kim YM, Ahnn J, Kwon DY, Takaya Y, Wataya Y, Kimm HS. The antimalarial activity of herbal extracts used in traditional medicine in Korea. Biol Pharm Bull. 2003; 26:16231624.

16. Luder CG, Bohne W, Soldati D. Toxoplasmosis: a persisting challenge. Trends Parasitology. 2001; 17: 460-463.

17. Pappas G, Roussos N, Falagas M. Toxoplasmosis snapshots: Global status of Toxoplasma gondii seroprevalence and implications for pregnancy and congenital toxoplasmosis. Int J Parasitol. 2009; 39: 1385-1394.

18. Athanasiadou S, Githiori $J$ and Kyriazakis I. Medicinal plants for helminth parasite control: Facts Fiction. 2007; 1: $1392-1400$.

19. Leepin A, Stüdli A, Brun R, Stephens CE, Boykin DW, Hemphill $A$. Host cells participate in the in vitro effects of novel diamidine analogues against tachyzoites of the intracellular apicomplexan parasites Neospora caninum and Toxoplasma gondii. Antimicrob. Agents Chemother. 2008; 52:1999-2008.

20. Villena I, Aubert D, Leroux B, Dupouy D, Talmud M, Chemla $C$, Trenque $T$, Schmit $G$, Quereux $C$, Guenounou $M$, Pluot $M$, Bonhomme A, Pinon JM. Pyrimethamine-sulfadoxine treatment of congenital toxoplasmosis: follow-up of 78 cases between 1980 and 1997. Reims Toxoplasmosis Group. Scand J Infect Dis. 1998; 30: 295-300.

21. Choi KM, Gang J, Yun J. Anti-Toxoplasma gondii RH strain activity of herbal extracts used in traditional medicine. Int J Antimicrob Agents. 2008; 32:360-362. 
Devanthran et al

22. Strob/ JS, Cassell M, Mitchell SM, Reilly CM, Lindsay DS. Scriptaid and suberoylanilide hydroxamic acid are histone deacetylase inhibitors with potent anti-
Toxoplasma gondii activity in vitro. J Parasitol 2007; 93: 694-700. 